\title{
LA “LEY BOX” Y LA PRENSA MEXICANA (1929-1930)
}

\author{
Fernando Saúl Alanís Enciso \\ El Colegio de San Luis
}

Ender ntre 1924 y 1930, John Calvin Box (1871-1941), congresista demócrata por el estado de Texas, llevó a cabo una intensa labor en el Comité de Inmigración y Naturalización de la Cámara de Representantes del Congreso de Estados Unidos para que fuera aprobada una ley que impusiera una cuota a la inmigración procedente de México, lo que significaba que solo se permitiría el ingreso de 1500 personas anualmente. ${ }^{1}$ Su iniciativa se basaba en la idea de que los trabajadores mexicanos eran una amenaza económica y social para esa nación. Según él, afectaban a los pequeños productores agrícolas de varias regiones al bajar los costos de producción de las grandes empresas agrícolas. Asimismo, consideraba que racialmente eran inferiores por su origen mestizo (mezcla de español e indígena), lo cual los hacía muy diferentes racial, social y culturalmente a la población blanca estadounidense, por lo tanto, eran personas poco convenientes para ingresar a Estados Unidos.

Fecha de recepción: 1으 de octubre de 2018

Fecha de aceptación: 5 de julio de 2019

${ }^{1}$ ReIsLer, By the Sweat, p. 207. 
En México, la propuesta de Box llamó la atención de algunos periódicos, especialmente en 1929 y los primeros meses de 1930. Se publicaron numerosas notas acerca de los objetivos que buscaba el congresista texano, sobre quienes lo apoyaban, sus detractores, así como los diferentes momentos en que se sostuvieron los debates de la propuesta en el Comité de Inmigración del Senado y en la Cámara de Representantes. También difundieron el rumor de que la iniciativa se había convertido en ley y había entrado en vigor -aunque nunca fue aprobada-, así como las supuestas deportaciones que estaba provocando, entre los principales temas. Asimismo, manifestaron enojo por los límites que proponía al ingreso de inmigrantes mexicanos a Estados Unidos.

El propósito de este trabajo es responder la pregunta ¿por qué llamó la atención de la prensa mexicana una propuesta de ley, la de John Box, que nunca entró en vigor -es decir, algo que en los hechos nunca se dio-, en particular en 1929 y la primera mitad de 1930, cuando dejó de discutirse en el Congreso estadounidense y Box ya no fue reelegido para seguir participando en esa institución? La hipótesis de este artículo es que despertó el interés de parte del público mexicano por dos razones. La primera es que fue amplia la creencia de que era una ley que había sido aplicada para deportar a mexicanos en Estados Unidos, a causa de que se le relacionaba, y confundía, constantemente con dos medidas que el gobierno de aquel país tomó en esos años. Por un lado, la Ley de Inmigración promulgada el 4 de marzo de 1929, también conocida como Ley de Extranjería Indeseable (Undesirable Aliens Act 5094), la cual tenía como objetivo castigar a los inmigrantes que ingresaran sin documentación legal a ese país y, por otro lado, la campaña de deportación federal que el Departamento del Trabajo y el Servicio de Inmigración y Naturalización emprendieron en el sur de Texas, la cual comenzó a mediados de 1928, se intensificó en 1929 y abarcó hasta 1931. Es decir, la prensa interpretó la iniciativa de Box atribuyéndole 
el carácter de ley y acciones que tenían que ver con otras decisiones destinadas a frenar la inmigración ilegal y deportar. Esas creencias tomaron tal fuerza que formaron, inventaron, la idea de que la propuesta de Box era una legislación que estaba provocando la migración de retorno que ocurrió en esa etapa -antes de que comenzara el regreso en gran escala a consecuencia de la Gran Depresión, lo que se conoce como repatriación-. El segundo motivo es que varios escritores y editorialistas consideraron que la iniciativa de Box era ofensiva para México y sus ciudadanos por los criterios raciales con que deseaba establecer límites a la inmigración de ese país. Desde ese punto de vista, era una propuesta con claros tintes racistas que llevó a que aparecieran comentarios de rechazo y opiniones acerca de que hería a México y sus residentes.

Antes de 1929 no había motivo para que actores mexicanos mostraran alguna inconformidad $\mathrm{u}$ otras opiniones respecto a la propuesta de Box, debido a que no prosperó en el Congreso; la Ley de Inmigración de 1924 no contemplaba a México dentro del sistemas de cuotas. ${ }^{2}$ Asimismo, las reglamentaciones dirigidas a frenar el flujo migratorio en la frontera con México fueron flexibles al ingreso de estos migrantes. De igual modo, no hubo medidas extraordinarias para promover su expulsión ni la prensa mexicana las mezcló con la propuesta de Box. En ese ámbito, entre 1924 y 1928, llamó poco la atención del público mexicano.

El análisis de este trabajo se basa principalmente en notas y opiniones vertidas en tres periódicos: El Siglo de Torreón, Torreón, Coahuila; El Informador, Guadalajara, Jalisco, y El Tucsonense, Tucson, Arizona. Los dos primeros los elegí por la facilidad de consultarlos en línea, mientras que el tercero lo revisé en la biblioteca de la Universidad de Arizona, Tucson; en ellos encontré cuantiosa información y editoriales sobre el

2 Zolberg, A Nation by Design, pp. 243, 250-254. Divine, American Immigration, p. 28. 
tema. ${ }^{3}$ También los estudié porque, a diferencia de otros que se publicaron en los estados de la República en la misma época, estos han conservado las series completas de la publicación, por lo cual me fue posible dar un seguimiento al tema mes a mes. Con este propósito, revisé otros del interior de la República (El Intruso, Cananea, Sonora; Acción, San Luis Potosí; El Correo, León, Guanajuato; Labor, Irapuato, Guanajuato, y el Periódico Oficial del Estado de Colima), pero solo encontré algunos ejemplares, los cuales me ayudaron a complementar los comentarios y los argumentos centrales en este estudio. Además, examiné dos de los periódicos más importantes de la Ciudad de México, El Universal y Excelsior, que publicaron algunas notas al respecto, las cuales contribuyeron asimismo a mejorar el análisis. Falta hacer una investigación más amplia y profunda en otros diarios del interior del país (Monterrey, Nuevo León, Aguascalientes, Guanajuato, Michoacán, Chihuahua, Hermosillo, Sonora, entre otros), que se pueden consultar físicamente en los lugares de origen o en la Hemeroteca Nacional de la Ciudad de México, aspecto que rebasa el propósito de este trabajo.

El Siglo de Torreón fue un diario independiente con una línea editorial crítica al gobierno, fundado en 1922 por el empresario Antonio Juambelz y Bracho. Este era considerado el periódico más importante de la Comarca Lagunera (región conformada por municipios del estado de Coahuila y Durango). ${ }^{4}$ Por su parte, El Informador fue un periódico de línea editorial conservadora, fundado en 1917 por Jesús Álvarez del Castillo, el cual se cuidó de no adoptar posturas demasiado críticas hacia el gobierno y otros sectores importantes de la sociedad

3 Véase la Hemeroteca Digital de El Informador, Diario Independiente, en http://hemeroteca.informador.com.mx, y la Hemeroteca Digital de El Siglo de Torreón en http://h.elsiglodetorreon.com.mx/Default/Skins/ElSiglo/Client. asp?Skin=ElSiglo

4 El Siglo de Torreón (6 dic. 2007), en https://www.elsiglodetorreon.com.mx/ noticia/316095.antonio-de-juambelz-se-adelanto-al-futuro.html 
jalisciense o mexicana en general. ${ }^{5}$ En tanto, El Tucsonense fue un diario fundado en 1915 en Tucson, Arizona, por Francisco S. Moreno, quien nació en Hermosillo, Sonora (1877). El nexo con el espacio familiar sonorense, como lo tenían muchos lectores en Arizona, fue un factor para que este impreso, además de tratar aspectos políticos y económico relevantes de la vida estadounidense, diera cuenta de los acontecimientos en el sur de la frontera, con contenidos regionalistas y de corte patriótico. ${ }^{6}$ Este último lo incluí porque cubrió de una manera amplia y detallada la iniciativa de Box a lo largo de 1929 y comienzos de 1930. Asimismo, a pesar de que no se publicaba en México, al igual que otros periódicos de la comunidad mexicana en Estados Unidos (entre los principales La Prensa, de San Antonio, Texas, y La Opinión, de Los Ángeles, California), informaba sobre los acontecimientos más relevantes de la vida política y económica en México y emitía opiniones sobre el acontecer social y político de este país. En ese sentido, también forma parte de la prensa mexicana, más allá de las fronteras, pues mantenía una relación estrecha con el país de origen de sus fundadores.

Las publicaciones consultadas son representativas de tres espacios regionales diferentes: el occidente y el noroeste de México y el suroeste de Estados Unidos. Lo destacado es que, aunque tenían una posición editorial distinta (antioficial, conservadora y crítica-patriótica) y el radio geográfico de distribución e influencia de cada uno era diferente, sus opiniones en relación con la propuesta de John Box fueron coincidentes, tal como lo muestra este artículo. Es decir, ciertos círculos de la sociedad mexicana, con independencia del lugar en donde se encontraban, aun fuera de México, reaccionaron de forma parecida. Algo que también muestran es que el tema pudo llamar más la atención en algunas zonas de tradición migratoria: norte y occidente de

5 SÁnchez, "Apuntes para una historia”, p. 13.

${ }^{6}$ Murrieta, "El general Obregón”. 
México, por el temor del posible impacto de la puesta en vigor de la iniciativa de Box, incluso entre la comunidad mexicana en Estados Unidos.

Otra razón por la cual empleé principalmente periódicos para el análisis es que existen pocos documentos oficiales de la administración pública federal mexicana (Secretaría de Gobernación y Secretaría de Relaciones Exteriores) y local (gobiernos estatales y municipales) que hayan tratado el tema. Esta escasez se debe a que no fue tema central en la agenda de la política nacional ni bilateral. En el ámbito interno, los temas que ocuparon la atención fueron la creación de una institución que garantizaría la pacificación de los distintos jefes militares, así como el dominio del general Plutarco Elías Calles sobre los acontecimientos y los personajes políticos (el Partido Nacional Revolucionario, marzo de 1929); la atención al levantamiento en su contra (la llamada rebelión escobarista, encabezada por el general José Gonzalo Escobar, en oposición del presidente Emilio Portes Gil, mayo de 1929), y la solución del conflicto con la Iglesia que se venía dando desde 1926 (la Guerra Cristera y los acuerdos que pusieron fin a esta en julio de 1929)..$^{7}$ En cuanto a la relación bilateral, esta se encontraba en un punto de entendimiento de los asuntos más críticos que a Estados Unidos le interesaba resolver: el problema petrolero y el artículo 27 de la Constitución promulgada en 1917, que tantas tensiones había causado con aquel país, ${ }^{8}$ y la reestructuración de la deuda externa (acuerdo Montes de Oca-Lamont con el Comité Internacional de Banqueros en julio de 1930)..${ }^{9} \mathrm{La}$ atención del

\footnotetext{
7 Meyer, Segovia y Lajous, Historia de la Revolución Mexicana, vol. 12, pp. 64-84.

8 Knight, U.S.-Mexican Relations, 1910-1940, pp. 30-34. MeYer, México y Estados Unidos, pp. 283-296.

9 Meyer, México y Estados Unidos, pp. 283-296. Riguzzi y De los Ríos, Las relaciones México-Estados Unidos, pp. 246-263. VÁzquez y Meyer, México frente a Estados Unidos, pp. 157-160.
} 
gobierno de Emilio Portes Gil (1929-1930) -bajo la sombra del Jefe Máximo, general Plutarco Elías Calles (1924-1928), quien en realidad gobernaba el país- estaba puesta en la consecución de acuerdos con Estados Unidos en relación con esos temas. ${ }^{10}$ En lo tocante a las relaciones entre naciones, este artículo muestra que, a diferencia del medio oficial, la prensa dio cierta importancia a la propuesta de Box porque consideró que lesionaba tales relaciones ya que México no recibía el trato que merecía por ser, según ella, vecino y aliado, por lo cual demandaba que el gobierno mexicano emitiera una protesta. También se mostró a favor de medidas más radicales, como negar el ingreso a los ciudadanos estadounidenses y expulsar a los que estaban en México, y por el boicot comercial contra productos de aquel país.

Además, la iniciativa de Box no causó gran preocupación en el círculo oficial, ya que, por un lado, nunca se convirtió en ley, por lo que no se aplicó como tal a los migrantes mexicanos -a pesar de la creencia de muchos- y, por el otro, la política internacional del gobierno mexicano de aquel entonces era que los demás países no se metieran en los asuntos internos de México ni este en los de otros países - principios de no intervención y autodeterminación, conocidos como Doctrina Carranza (1917), pieza central de la diplomacia revolucionaria, y Doctrina Estrada de 1930-. ${ }^{11}$ En ese sentido, la discusión de una cuota a la inmigración mexicana era un asunto interno de Estados Unidos, sobre el cual representantes de la clase política tuvieron precaución de emitir comentarios. Esto no quiere decir que algunos funcionarios de la Secretaría de Gobernación y de la Secretaría de Relaciones Exteriores no estuvieran atentos a las posibles consecuencias en caso de aprobarse en el Congreso de Estados Unidos y convertirse en ley. En ese sentido, este trabajo muestra

${ }^{10}$ Knight, U.S.-Mexican Relations, 1910-1940, pp. 30-34. MeYer, México y Estados Unidos, pp. 283-296.

11 Covarkubias, “Los principios y la política exterior”, pp. 387-422. YANKeLEVICH, “América Latina en la agenda”, pp. 277-312. 
que hubo algunos pronunciamientos a favor de la protección de sus ciudadanos y que algunos funcionarios y medios oficiales llegaron a considerar que podría tener efectos positivos en dos vías: por un lado, contribuiría a frenar la salida de trabajadores y, por el otro, fomentaría el retorno de migrantes que, con su experiencia laboral en aquel país, podrían venir a México a colonizar y trabajar en los proyectos de irrigación impulsados en esa época.

La iniciativa del senador Box ha sido ampliamente estudiada. Existen trabajos en los que se analiza en detalle la trayectoria de Box como congresista, sus principales propuestas y la visión de este sobre la inmigración mexicana. ${ }^{12}$ También hay estudios que examinan la propuesta desde el ámbito local, en especial en Texas, de donde era originario y donde su iniciativa contó con un gran apoyo de poderosos grupos nativistas y nacionalistas que se oponían a la inmigración mexicana. ${ }^{13}$ Asimismo, hay estudios de las políticas de inmigración de Estados Unidos en las primeras décadas del siglo xx, los cuales destacan el notable papel que Box desempeñó durante la segunda mitad de la década de los veinte como cabeza de los actores que se pronunciaron a favor de la implantación de una cuota migratoria al hemisferio occidental, en particular a México. ${ }^{14}$ Igualmente, mencionan la oposición que su propuesta enfrentó y la visión que tenía acerca de los migrantes mexicanos. ${ }^{15}$ La historiografía sobre la migración mexicana a Estados Unidos también ha examinado los pasajes más relevantes de la iniciativa de Box, sobre todo el intenso debate y los argumentos de este, que se sostuvo en los

\footnotetext{
12 Marshall, “The Box Bill”. Otey, “Shrugging Atlas”.

13 Weber, “Homing Pigeons”, pp. 167-186. Foley, The White Scourge, pp. 77-80.

14 Divine, American Immigration. Lukens, A Quiet Victory. Allerfeldt, “And We Got Here First”, pp. 7-26. Zolberg, A Nation by Design. Reisler, “Always the Laborer”, pp. 231-254.

15 Molina, “'In a Race All Their Own”, pp. 167-201.
} 
años veinte entre los grupos que apoyaban medidas contra la inmigración mexicana (por motivos raciales, sociales y económicos) y quienes se oponían al establecimiento de acciones para limitar el ingreso de trabajadores mexicanos porque consideraban que el impacto económico en ciertas áreas sería catastrófico. ${ }^{16}$ Cabe señalar que ninguno de estos trabajos se cuestiona por qué la propuesta de Box llamó la atención de la prensa mexicana a partir de 1929 y no antes, así como cuáles fueron las principales opiniones que provocó en la sociedad mexicana.

La historiografía sobre la repatriación de mexicanos de Estados Unidos durante la Gran Depresión (1929-1934) también le ha dedicado un espacio al tema, ya que toma en cuenta una parte importante de las iniciativas contra la inmigración mexicana de esos años; aunque, en realidad, como lo muestra este trabajo, fue un proceso que se desenvolvió antes de la recesión y la migración en gran escala que esta provocó. Carreras de Velasco menciona que la iniciativa se usó como pretexto para llevar a cabo deportaciones y favoreció el control de los que deseaban ingresar a ese país. Señala que la "prensa mexicana se llenó de comentarios al respecto" -aunque no los examina-.$^{17}$ Alanís Enciso también hace alusión a la propuesta de Box como parte de las medidas que surgieron en Estados Unidos en los años veinte y tomaron fuerza a comienzos de los treinta contra la inmigración de personas de origen mexicano y a favor de la deportación de estas. ${ }^{18}$ Menciona brevemente que algunos periódicos manifestaron que la iniciativa hería a México y a sus ciudadanos por los criterios raciales con que deseaba establecer límites a la inmigración de ese país, así como algunos insultos a Estados Unidos, pero no profundiza en los discursos de la prensa. Balderrama y Rodríguez citan la propuesta de Box entre las iniciativas de

16 Reisler, By the Sweat. Cardoso, Mexican Emigration, pp. 136-140.

17 Carreras de Velasco, Los mexicanos que devolvió, pp. 33, 35, 60, 115.

18 Alanís, Voces de la repatriación, pp. 93-110. 
leyes contra la inmigración que se introdujeron en el Congreso de Estados Unidos. Mencionan que periódicos en México y diarios publicados en español en Estados Unidos promovieron una vigorosa campaña contra Estados Unidos y sus actitudes racistas, y se pronunciaron a favor de que la propuesta no fuera aprobada. ${ }^{19}$ Ellos tampoco hacen un examen de las opiniones de los periódicos. En general, aquellos que han estudiado la repatriación durante la recesión mencionan que la propuesta de Box provocó reacciones en la prensa mexicana y en la mexicana en Estados Unidos, pero no cuestionan por qué surgieron estas en ese momento ni las razones por las cuales esta propuesta llamó la atención del público mexicano.

\section{LAS ETAPAS DE LA PROPUESTA Y LOS CONTEXTOS}

La iniciativa de John Box en pro del establecimiento de una cuota a la inmigración mexicana y las reacciones que provocó en México se pueden dividir en dos grandes etapas. La primera fue de 1924 a 1928, y se caracteriza por los primeros intentos de Box de modificar la ley vigente a fin de imponer una cuota migratoria a México; asimismo, por su oposición a cualquier tipo de medida que permitiera el ingreso de mexicanos, incluso la migración temporal de trabajadores agrícolas. En ese momento, su propuesta no era considerada una prioridad entre las leyes de inmigración que aprobaron el Senado y la Cámara de Representantes; esta afrontaba una fuerte oposición de poderosos grupos económicos, y, sobre todo, no surgieron legislaciones para impedir el ingreso de la migración mexicana ni para promover su expulsión. Por si fuera poco, el contexto económico favoreció el ingreso de inmigrantes procedentes de México, lo cual ayudó a que su iniciativa tuviera poca notoriedad en ese país.

19 Balderrama y Rodríguez, Decade of Betrayal, p. 18. 
Desde 1924, Box, como integrante del Comité de Inmigración y Naturalización de la Cámara de Representantes, se había mostrado a favor de que la inmigración mexicana fuera restringida. ${ }^{20}$ Durante la discusión de la Ley de Origen Nacional, él encabezó al grupo restriccionista que estaba a favor de la aplicación del principio de cuotas tanto a países de Europa como del continente americano, en especial a México. ${ }^{21}$ Además, impulsó un proyecto de ley (Resolución de la Cámara 6741 de la primera sesión del $69^{\circ}$ Congreso) por medio de la cual se enmendaría la de Inmigración de 1924 al limitar la inmigración de México a $2 \%$ de la población mexicana en Estados Unidos según lo registrado por el censo de 1890; con ello, México se agregaría a la lista de países con cuotas, y solo se permitiría el ingreso de 1500 personas. ${ }^{22}$ Aunque algunos miembros de la Cámara de Representantes apoyaban las ideas de Box, la restricción a México no fue considerada un problema importante en la sesión 69 del Congreso (diciembre de 1926-marzo de 1927), pues la atención seguía en contener la inmigración del este y el sur de Europa. Box también se opuso a la idea de permitir el ingreso temporal de trabajadores agrícolas mexicanos que el congresista Bird J. Vincent de Michigan introdujo en las audiencias de 1926 del Comité de Inmigración y Naturalización de la Cámara de Representantes. Consideraba que, si la propuesta funcionaba de manera correcta, sancionaría el peonaje en violación de la Constitución, lo cual, desde su punto de vista, era incongruente con el principio nacional de la libertad individual. Asimismo, en caso de no funcionar adecuadamente, permitiría la presencia de un pueblo indeseable, el mexicano. ${ }^{23}$

20 Marshall, “The 'Box Bill' ”, p. 24. Reisler, By the Sweat, p. 200.

21 Reisler, By the Sweat, p. 200. Divine, American Immigration, p. 28.

22 Marshall, “The 'Box Bill' ", p. 23.

23 Reisler, By the Sweat, pp. 200-203. Lukens, A Quiet Victory, p. 55. Zolberg, $A$ Nation by Design, p. 257. Allerfeldt, “And We Got Here First”, p. 18. 
Durante febrero y marzo de 1928, el Senado y la Cámara de Representantes entablaron una serie de debates en torno de los proyectos de ley para limitar la inmigración procedente del hemisferio occidental. El patrocinador principal fue nuevamente John Box. Aunque contaba con el apoyo de sindicatos, pequeños agricultores, trabajadores sociales, eugenistas y organismos para la asistencia pública, tropezó con una oposición formidable. Agricultores y cultivadores, respaldados por la poderosa Cámara de Comercio de Los Ángeles, habían agrupado a representantes de la agricultura, los ferrocarriles y la industria para convencer a los legisladores de que cerrar las puertas a la mano de obra mexicana acarrearía un desastre económico para el suroeste. ${ }^{24}$ Los antirrestriccionistas contaban con el respaldo del Departamento de Estado, y los que estaban a favor de la restricción, con el del Departamento de Trabajo. Los primeros montaron un exitoso ataque al proyecto de ley de Box, lo que les permitió derrotarlo. Asimismo, fue fundamental la valoración del Departamento de Estado acerca del impacto que esto tendría en el ámbito geopolítico, ya que se pensaba que una cuota al hemisferio occidental sería ofensiva y poco diplomática para varias naciones latinoamericanas, entre ellas México, que poco antes se habían reunido en La Habana, Cuba, en la Sexta Conferencia Panamericana (del 16 de enero al 28 de febrero). ${ }^{25}$

La iniciativa de Box era un reflejo de la posición de muchos políticos, líderes comunitarios y organizaciones civiles que se oponían de modo abierto a esta migración con fundamento en un rechazo racial. Representaba la postura de los eugenistas de atacar la afluencia de mano de obra barata desde una perspectiva racista. ${ }^{26}$ Asimismo, expresaba la parte radical opositora de

${ }^{24}$ Lukens, A Quiet Victory, pp. 55, 60-61. Divine, American Immigration, pp. 35-41.

${ }_{25}$ Hoffman, "El cierre de la puerta”, pp. 405-406.

${ }^{26}$ Marshall, “The 'Box Bill” ”, p. 21. Foley, The White Scourge, pp. 60-70. 
aquellos que habían discutido y estudiado la migración mexicana en los comités de la Cámara de Representantes y el Senado en la década de los años veinte. Box y los restriccionistas sostenían tres argumentos centrales por los cuales el Congreso debería colocar a México en un sistema de cuotas: cuestiones económicas (pérdida de empleos entre los estadounidenses nativos), diferencias raciales, sociales y culturales entre los estadounidenses blancos y los inmigrantes latinos, y simple "igualdad legislativa" entre México y las naciones europeas que ya estaban bajo la cuota. ${ }^{27}$

El contexto económico del primer periodo en la historia de los trabajos de Box se caracterizó por el auge y la gran demanda de mano de obra mexicana en diferentes sectores de la economía de Estados Unidos, sobre todo en el agrícola, lo cual favoreció una migración numerosa de brazos procedente de México -Manuel Gamio, destacado antropólogo que realizó estudios sobre la migración, calculó que salieron cerca de 296951 personas $(1924,57269 ; 1925,41759$; 1926, 56534; 1927 , 76209 y 1928,65180$)-.{ }^{28}$ La salida también se incrementó a causa de las condiciones de inseguridad en ciertas partes del centro-occidente de México derivadas de la Guerra Cristera (1926-1929). ${ }^{29}$ El periodo destaca en general porque, si bien en el Congreso de Estados Unidos hubo debates en torno del establecimiento de una cuota a la inmigración mexicana, el gobierno federal no tomó otras medidas o aprobó alguna ley que evitara la entrada de inmigrantes mexicanos o promoviera su expulsión. En ese entorno, la propuesta de Box no llamaba la atención de la sociedad mexicana de manera singular. Algunos periódicos

27 Lukens, A Quiet Victory, pp. 58-59, 36, 60-61. Divine, American Immigration, pp. 35-41. Marshall, “The 'Box Bill” ”, pp. 2-3, 23. Montejano, Anglos and Mexicans, pp. 157-256.

28 Gamio, Número, procedencia, p. 2, tabla III.

29 Young, Mexican Exodus. Young, “Cristero Diaspora”, pp. 271-300. 
en México y la prensa mexicana en Estados Unidos publicaron solo unas cuantas notas en 1928 y muy pocas antes de ese año. ${ }^{30}$

La segunda etapa de la propuesta de Box fue de 1929 a mayo de 1930. En ese momento, la prioridad en materia de flujos migratorios para el Senado y la Cámara de Representantes seguía siendo legislar para mantener las cuotas a los flujos migratorios procedentes de ciertas partes de Europa. Debido a ello y a la oposición de los grupos antirrestriccionistas no se aprobó una cuota para México. No obstante, el gobierno federal tomó medidas sin precedentes dirigidas a limitar la inmigración mexicana en general, penalizar a los migrantes que ingresaran sin documentos legales y realizar acciones para expulsarlos.

En 1929 comenzó el 71 Congreso (del 4 de marzo de 1929 al 4 de marzo de 1931), en el que Box volvió a presentar su proyecto. Los integrantes del Comité de Inmigración de la Cámara de Representantes centraron el debate en dilucidar si debería aplicarse el sistema de orígenes nacionales (national origins) a México o si debería tratarse a este país de manera independiente, como lo hicieron con Japón y China en la Ley de 1924. Ni la iniciativa de Box ni las discusiones del Comité de Inmigración tuvieron éxito debido a que algunos personajes como el senador David Reed, junto con Albert Johnson, autor de la Ley de Inmigración de 1924, consideraban que no sería necesario colocar a México en un sistema de cuotas. Creían prioritario mantener relaciones cordiales con México, y la aprobación de una ley de inmigración, que parecía ir contra esa nación, no era un buen indicador. Otro motivo que llevó a no aprobar la propuesta de Box fue que, durante los últimos días de la sesión, la atención se desvió hacia la caída del mercado bursátil de octubre, lo cual marcaba el inicio de la Gran Depresión. ${ }^{31}$

30 El Informador (20 mar. 1926 y 13 mar. 1928). El Siglo de Torreón (19 oct. 1928 y 27 febr. 1928). El Tucsonense (14 abr. 1927). Véase también El Fronterizo. Semanario de los Mexicanos en Arizona, Tucson, Arizona (3 mar. 1928).

31 Lukens, A Quiet Victory, p. 58. 
Aun cuando no se decretó una cuota migratoria para México, la administración del presidente Calvin Coolidge (de agosto de 1923 a marzo de 1929) tomó dos resoluciones para frenar la inmigración legal e ilegal de México, en gran medida como respuesta a la demanda de los grupos nativistas y restriccionistas que no habían tenido éxito en el Congreso. Primero, en enero de 1929, el secretario de Estado Kellogg ordenó a los cónsules estadounidenses en México la restricción del número de visas. Para ello tenían que hacer cumplir con rigor las normas de inmigración existentes. Entonces los cónsules aplicaron la prueba de alfabetización según la cual cualquier inmigrante que deseara ingresar debía saber leer y escribir en algún idioma. Lo más importante es que comenzaron a imponer prohibiciones contra los trabajadores subcontratados y, por primera vez desde su promulgación en la Ley de Inmigración de 1917, se puso en práctica la disposición de no permitir el ingreso a personas tendientes a convertirse en una carga pública por no contar con los medios suficientes para vivir (conocida como la cláusula L.P.C., liable to become a public charge). Estos cambios administrativos resultaron en una extrema disminución de visas y entradas legales desde México. Los oficiales consulares negaron la entrada a la mayoría de los mexicanos que solicitaron visa. Antes de la emisión de esas órdenes, el Departamento de Estado había expedido entre 5000 y 6000 visas por mes a ciudadanos mexicanos. Esas cantidades disminuyeron a poco más de 2000 visas por mes. A fines de noviembre, el número de cruces fronterizos legales documentados se redujo en $25 \% .^{32}$ Las cifras oficiales de inmigración también muestran que el ingreso fue descendiendo: 1928, 59016; 1929, $40154,1930,12703.33$

La segunda medida fue la aprobación en el Congreso de la Ley de Extranjería Indeseable del 4 de marzo de 1929, que fue

32 Lukens, A Quiet Victory, pp. 52-57.

33 Weber, "Homing Pigeons", pp. 41-42. 
impulsada por el senador Coleman Blease, supremacista blanco de Carolina del Sur, la cual estableció que cualquier entrada sin inspección sería calificada como "un delito menor". Entonces, después de esa fecha, cualquier extranjero que ingresara a Estados Unidos por un lugar que no fuera un puerto de entrada oficial, designado por los funcionarios de inmigración, sería culpable de infringir la ley y, en caso de condena, sería castigado con prisión por no más de un año o por una multa de no más de 1000 dólares, o por ambos. ${ }^{34}$ Asimismo, determinó que el reingreso después de la deportación se consideraría un delito grave y se castigaría con multa y encarcelamiento. ${ }^{35}$ Con estas medidas, los cruces fronterizos no autorizados pasaron de ser delitos menores a graves, con castigo de prisión por dos a cinco años y una multa de 10000 dólares por la comisión del segundo delito. Esta fue la forma en que se criminalizó la entrada ilegal a Estados Unidos, la cual sometió a los detenidos a largas penas carcelarias y costosas multas antes de la deportación. El estatuto fue rápidamente puesto en práctica. Entre julio de 1929 y junio de 1930, según un informe del Departamento de Trabajo, los fiscales presentaron más de 6000 casos de ingreso ilegal. ${ }^{36}$ Fue la culminación de los esfuerzos federales por controlar las fronteras terrestres de Estados Unidos, dirigidos a detener el tráfico de inmigrantes y la entrada ilícita en las fronteras del norte y el sur, que se venían dando desde principios del siglo xx. Ello condujo a la construcción de un "nuevo sentido de territorialidad" y acentuó el poder del Estado y sus medidas burocráticas encaminadas al control de los cruces fronterizos. ${ }^{37}$

Además de la restricción del visado y el establecimiento de una ley para penalizar el ingreso ilegal, el Departamento

34 Corwin y Mccain, “Wetbackism since 1964”, p. 86.

35 Bulletin, Immigration Legislation, pp. 280-281. NGaI, “The Strange Career of the Illegal Alien”, p. 76.

36 Hernández, Migra! y Garza, They Came to Toil, p. 35.

37 Ngai, Impossible Subjects, pp. 1-20. ETTINGER, Imaginary Lines, pp. 1-25. 
de Trabajo y el Servicio de Inmigración y Naturalización iniciaron deportaciones en gran escala de mexicanos en el sur de Texas. El argumento para llevarlas a cabo era que habían cometido violaciones de las leyes de inmigración vigentes. Las primeras campañas ocurrieron en mayo de 1928, en las cercanías de la ciudad de Donna, en el Valle del Río Grande, y se intensificaron entre 1929 y 1931. Se efectuaron redadas tanto en áreas urbanas como rurales; la actividad más intensa se verificó en la frontera entre México y Texas. Se dirigieron principalmente a barrios y lugares de trabajo donde prevalecía la presencia de personas de origen mexicano. Estas deportaciones surgieron directamente del deseo de los grupos nativista en el Congreso de frenar la inmigración de México. Frustrados sus intentos de incluir a ese país en las leyes de cuotas, tanto en 1926 como en 1928, los funcionarios idearon deportaciones en gran escala en el Valle del Río Grande. ${ }^{38}$ Así, 1929 fue un año particularmente intenso en medidas contra el ingreso de inmigrantes mexicanos y a favor de su expulsión. Estas produjeron un clima de temor, persecución y confusión entre la comunidad mexicana en Estados Unidos. Muchos pensaban que serían deportados con base en la Ley de Extranjería Indeseable, lo cual en realidad no estaba contemplado en dicha legislación; otros consideraban que las deportaciones tenían su origen en esa ley, lo cual tampoco era verdad. Varios mexicanos que vivían en el sur de Texas creían que Estados Unidos estaba enviando a todos los mexicanos de regreso a México. ${ }^{39}$ La difusión de las penalizaciones por ingresar sin documentación legal y de las noticias de las expulsiones en el sur de Texas contribuyó a crear un clima de zozobra. Como telón de fondo estaba la propuesta de John Box, respaldado por un amplio sector de la sociedad estadounidense,

38 Weber, “Homing Pigeons”, pp. 43, 169, 183-184. Walsh, Building the Borderlands, pp. 98-99.

39 MскаY, “Texas Mexican Repatriation”, pp. 98-119, 125. 
que, con base en argumentos racistas, luchaba arduamente en el Congreso a fin de imponer un límite determinante al ingreso de inmigrantes mexicanos. Ello hizo que la iniciativa tuviera mayor visibilidad en México y que, como se verá más adelante, se relacionara y confundiera con las medidas tomadas para expulsar a los mexicanos de ese país.

La primera mitad de 1930 fue decisiva en la historia de la iniciativa de Box. En el Comité de Inmigración de la Cámara de Representantes, insistió en la restricción de la inmigración de México debido al desempleo causado por la recesión. A inicios de mayo, intentó apresurar la votación en el Comité de Inmigración con la esperanza de que su propuesta se aprobara, ya que el Senado había aceptado el proyecto del senador William J. Harris, del estado de Georgia, que contemplaba a los países del hemisferio occidental en la cuota de inmigración, entre los que estaba México, lo cual habría limitado la inmigración mexicana a 1500 por año (una cuota de $2 \%)^{40}$-aunque aún requería la aprobación de la Cámara de Representantes y la firma presidencial antes de entrar en vigor, lo cual no sucedió-. Debido a que la propuesta de Harris coincidía con la de Box, este decidió apoyarla, por lo que fue conocida popularmente como Ley Harris-Box. Las protestas y la oposición de la administración del presidente Herbert Hoover (1929-1933) fueron evidentes, así como los esfuerzos que hicieron los líderes de la Cámara de Representantes para frenar la iniciativa Box. A finales de mayo, el Comité de Inmigración de la Cámara de Representantes informó que quedaba fuera de toda discusión. ${ }^{41}$

Fueron diversos los motivos para aminorar los esfuerzos legislativos a favor de una cuota migratoria para México y evitar que se convirtiera en ley. Entre los principales, las reservas

${ }^{40}$ Lukens, A Quiet Victory, pp. 59, 60-61. Divine, American Immigration, pp. 35-41. El Tucsonense (23 ene., 20 feb. 1930).

${ }_{41}$ Reisler, By the Sweat, pp. 201, 207, 213, 216-217. 
del presidente Hoover a firmarla y la oposición decidida del Departamento de Estado, pues había valorado el posible efecto negativo en los ámbitos diplomático y comercial para los inversionistas estadounidenses que operaban en la economía mexicana si el gobierno de México decidiera llevar a efecto el embargo o boicot contra las manufacturas estadounidenses en represalia por la iniciativa migratoria, así como las medidas exitosas que el Departamento de Estado estaba empleando para controlar el ingreso de inmigrantes mexicanos (la limitación del número de visas -de 40154 en 1929 a 12703 en 1930 y 3333 en 1931-, la aplicación de la prueba de alfabetismo, el cobro del impuesto de 8 dólares por ingreso, el intenso trabajo de los inspectores fronterizos y el incremento de la Policía Fronteriza), lo cual había hecho que la inmigración disminuyera significativamente (tan solo 434 por mes, por lo que algunos consideraban que el llamado "problema mexicano [ya no] se debía considerar seriamente"). En julio de 1930, la historia de la iniciativa impulsada por Box finalizó cuando este dejó de ser congresista al ser derrotado en las elecciones locales del estado de Texas. ${ }^{42}$

La segunda etapa de la iniciativa de Box se distinguió por tener como telón de fondos a) el debate entre restriccionistas y antirrestriccionistas acerca de la inmigración mexicana, el cual venía sosteniéndose desde mediados de la década de los veinte; b) la no aprobación de una cuota migratoria a México; c) las medidas adoptadas por el Departamento de Estado para restringir la expedición de visas a ciudadanos mexicanos; d) la puesta en marcha de una ley para castigar a los inmigrantes que ingresaban sin documentos legales, y e) la realización de la campaña de deportación en el sur de Texas que se inició a mediados de 1928 y se incrementó en 1929 y 1930. En un entorno caracterizado por la

42 Corwin, “A Story of Ad Hoc Exemptions”, pp. 146, 149, 184. Divine, American Immigration, pp. 65-66. Lukens, A Quiet Victory, pp. 35-36, 59-61, 62-65. Zolberg, A Nation by Design, pp. 268-70. El Informador (2 ago. 1930). 
adopción de medidas dirigidas a frenar la migración mexicana legal e ilegal a Estados Unidos y aquellas destinadas a expulsarlos, la prensa mexicana las mezcló con la propuesta de Box.

\section{LA DIFUSIÓN EN MÉXICO DE LA “LEY BOX” \\ Y EL RUMOR DE SU PUESTA EN MARCHA}

Desde 1929 hasta la primera mitad de 1930, algunos periódicos en México, sobre todo del centro y el norte, publicaron notas que daban cuenta de los aspectos más relevantes de la propuesta de John Box, razón por la cual no es de sorprender que la iniciativa se conociera en diversos círculos de la sociedad mexicana. El Siglo de Torreón informó acerca de los diversos momentos en que la iniciativa se presentó en el Comité de Inmigración del Senado y de la Cámara de Representantes de Estados Unidos. Igualmente, hubo noticias sobre los instantes en que esos organismos se reunieron, discutieron y votaron la propuesta de Box. ${ }^{43}$ El Universal, periódico fundado en 1916 por Félix Fulgencio Palavicini, con fuerte presencia en la ciudad de México, publicó algunas notas al respecto. ${ }^{44}$ El Informador también dio noticia de la derrota de Box en las elecciones locales para el Congreso en el estado de Texas. Ello fue relevante porque marcaba el fin de su controvertida iniciativa. ${ }^{45}$

Otro tema que refirieron los diarios que aquí se analizan fue el debate que se sostuvo dentro de Estados Unidos entre quienes estaban a favor de la propuesta de Box y aquellos que se oponían a esta. Las notas publicadas en El Siglo de Torreón resaltaban el rechazo de los grandes productores agrícolas de Texas, California, Arizona, Nuevo México y Colorado, los intereses del Valle del Río Grande, Texas, así como de la Cámara

\footnotetext{
${ }^{43}$ El Siglo de Torreón (9 feb. 1929; 15, 16, 27 mayo; 10 jun. y 29 jul. 1930).

${ }^{44}$ El Universal (23 mayo 1930).

${ }^{45}$ El Informador (2 ago. 1930).
} 
de Comercio Americana de México. ${ }^{46}$ De igual modo, la información difundida por El Informador, El Intruso, de Cananea, Sonora, así como por El Universal, dejó constancia de la oposición del presidente Hoover, el subsecretario de Estado Joseph Potter Cotton, el Departamento de Estado y los motivos de fondo para no aprobar el proyecto de Box: el deterioro de las relaciones entre los países y el hecho de que el Departamento de Estado había mostrado capacidad para controlar la inmigración mediante la aplicación estricta de las leyes vigentes. ${ }^{47}$ También aparecieron algunas declaraciones de Box acerca de la manera en que la maquinaria legislativa estaba suprimiendo su proyecto, las influencias que se encontraban detrás de ella y la aceptación de su derrota. ${ }^{48}$ En cuanto a los actores que respaldaban a Box, la información destacaba a la Federación Americana del Trabajo (American Federation of Labor), sociedades patrióticas, grupos organizados de trabajadores, el Ku Klux Klan y las opiniones de los senadores Albert Johnson, de Washington, Hugo Lafayette Black, de Alabama, y John Benjamin Kendrick, de Wyoming.49 Así, esos diarios mostraban la polarización que había en los círculos políticos, sociales y laborales de la sociedad estadounidense en relación con la iniciativa de Box.

El tópico que más llama la atención, de los que fueron abordados por los diarios, fue el rumor acerca de que la "Ley Box" había entrado en vigor. Fueron numerosas las noticias al respecto. En Torreón y en Guadalajara se difundieron informes acerca de que esta "ley" había comenzado a sancionarse desde el 4 de marzo de 1929. En mayo se hablaba de que se estaba aplicando con todo rigor a quienes no tenían sus papeles en regla o que

\footnotetext{
46 El Siglo de Torreón (16 mayo y 26 sep. 1929; 15 y 18 mayo, 14 jun. 1930). El Universal (24 mayo 1930).

47 El Informador (10 jun. 1930). El Intruso (10 jun. 1930). El Universal (16, 23 y 26 mayo 1930). El Siglo de Torreón (15 mayo 1930).

${ }^{48}$ El Informador (10 jun. 1930).

49 El Informador (18 abr. y 10 jun. 1930). El Universal (16 y 26 mayo 1930).
} 
para entrar a Estados Unidos habían violado las disposiciones migratorias, por lo que eran expulsados y deportados. ${ }^{50} \mathrm{El} \mathrm{In-}$ formador afirmaba que la "Ley Box" daba a las autoridades de migración la facultad de "correr a trompadas a nuestros nacionales del territorio americano". ${ }^{51}$ El Siglo de Torreón incluso aseguraba que la "Ley Box" se aplicaría de forma "retroactiva". ${ }^{2}$ Estas notas dan constancia de que, para ellos, la propuesta de Box era una ley que había entrado en vigor con el objeto de sancionar con la expulsión a aquellos que ingresaran a Estados Unidos sin documentación legal. Además, según su punto de vista, permitía a las autoridades migratorias expulsar de forma violenta a los mexicanos en ese país. Es claro que confundían la iniciativa de Box con la Ley de Extranjería Indeseable del 4 de marzo. Al mismo tiempo, a esa ley le arrogaban la iniciativa de impulsar deportaciones, lo cual no estaba estipulado en ninguna parte -más bien, eran resultado de la campaña de expulsión llevada a cabo por las autoridades en el sur de Texas-. Igualmente, hablaban de la retroactividad de la propuesta de Box, cuando esta nunca había sido contemplada; se referían de nuevo a la Ley de Extranjería Indeseable, la cual, como quedó establecido, entraría en vigor el 1 o de julio y se aplicaría de forma retroactiva a partir de mayo. Lo que muestran estas informaciones son los rumores que se habían creado alrededor de esa ley, las deportaciones y la propuesta de Box. En la prensa mexicana, tanto en México como en Estados Unidos, hubo una enorme confusión en la interpretación entre la propuesta de Box, así como sus objetivos, y las acciones y legislaciones que el gobierno federal promovía para frenar la inmigración ilegal y deportar a un gran número de mexicanos. En pocas palabras, se exageraron y tergiversaron los alcances de la iniciativa de Box.

50 El Siglo de Torreón (16 mayo 1929). El Informador (20 mayo 1929).

51 El Informador (20 mayo 1929).

52 El Siglo de Torreón (16 mayo 1929). 
A mediados del mismo año, otra nota aseguraba que, a causa de la entrada en vigor de la "Ley Box", los trabajadores mexicanos hacían gestiones para legalizar su estancia en Estados Unidos con el fin de que no los deportaran. ${ }^{53} \mathrm{La}$ información tergiversaba nuevamente los hechos, pues nunca existió una ley Box que dispusiera lo que afirmaba. Más bien, se refería a la Ley de Registro de Extranjeros del 2 de marzo de 1929 (Registry Act), por la cual el Congreso autorizaba la legalización y naturalización de las personas que habían vivido sin intermisión en Estados Unidos desde antes del 3 de junio de 1921 y no tuvieran registro de admisión a ese país. Otra vez, los periodistas confundían la propuesta de Box con otra ley. La nota del periódico no era clara sobre el tema, pues afirmaba que la legalización era para no ser objeto de expulsión, aspecto del que la Ley de Registro de Extranjeros no hacía referencia alguna, pero que fue central en la visión del periodista debido a la campaña de deportación en tierras tejanas. Ello muestra, de nuevo, la confusión, exageración y los rumores alrededor de las legislaciones promulgadas a comienzos de 1929 y la manera en que fueron ligadas a la propuesta de Box..$^{54}$

En Irapuato, Guanajuato, el diario Labor creía que medio millón de mexicanos regresarían debido a los problemas que los inmigrantes afrontaban en Texas con motivo de la "Ley Box". ${ }^{55}$ Por su parte, El Correo, de León, Guanajuato, informó que algunos cónsules mexicanos en Estados Unidos consideraban que eran "numerosísimos" los mexicanos que se preparaban a regresar a México como consecuencia de las dificultades que "la reciente Ley Box" les había ocasionado. ${ }^{56}$ Un editorialista del Excelsior, diario de la Ciudad de México fundado en 1917 por

53 El Siglo de Torreón (8 jul. 1929).

${ }^{54}$ KANG, The ins on the Line, pp. 56-57. Bulletin, Immigration Legislation, pp. 280-281.

${ }_{55}$ Labor (21 jul. 1929).

${ }^{56}$ El Correo (6 ago.1929). 
el periodista Rafael Alducin, entre otros, afirmaba que la "Ley Box" estaba siendo aplicada en sus preceptos fundamentales por el gobierno estadounidense. ${ }^{57}$ Por su parte, en Cananea, El Intruso informó que "109 mexicanos fueron deportados de acuerdo a lo estipulado en 'la Ley Box', en vigor a principios del año actual [1929]". ${ }^{58}$

A comienzos de 1930, los rumores persistieron. En mayo, El Siglo de Torreón informaba que, como resultado de la aplicación de la llamada Ley Box, las deportaciones de trabajadores mexicanos continuaban, cada vez más numerosas. ${ }^{59}$ El Universal aseguraba que "la Ley Box noquea" a los mexicanos; mientras Acción, de San Luis Potosí, afirmaba que a diario aumentaban las caravanas de repatriados que llegaban a Laredo y Matamoros, Tamaulipas, "expulsadas por las autoridades americanas de migración, de acuerdo con la Ley Box". ${ }^{60}$ El Universal publicó una caricatura, firmada por M. A. Montalvo, que ilustraba esta situación. En ella aparecen dos hombres de sombrero y zarape bajo un árbol. Uno le dice al otro, en spanglish -mezcla de español e inglés-, que había vivido en San Antonio, Texas, lugar en el que había trabajado en los "troques" (camionetas, sinónimo de troca, truck), pero por la ley Box había tenido que "combakearme" (regresarse) a México.

Las notas mencionadas en el párrafo anterior muestran la creencia extendida en diversas partes de México acerca de que: a) existió una ley llamada Box, b) que había entrado en vigor y se aplicaba a los inmigrantes mexicanos, c) que era una legislación encaminada a revisar el estatus legal de los inmigrantes, y d) que fue usada para expulsarlos. La idea de que había una ley Box tuvo su origen en la confusión de los medios entre esta y la Ley del Registro de Extranjeros (encaminada al registro y

\footnotetext{
57 Excelsior (28 ago. 1929).

58 El Intruso (23 nov.1929).

59 El Siglo de Torreón (2 mayo y 4 nov.1929).

60 El Universal (22 mayo 1930). Acción (10 dic.1930).
} 


\section{Denuestyos Onucursantes}

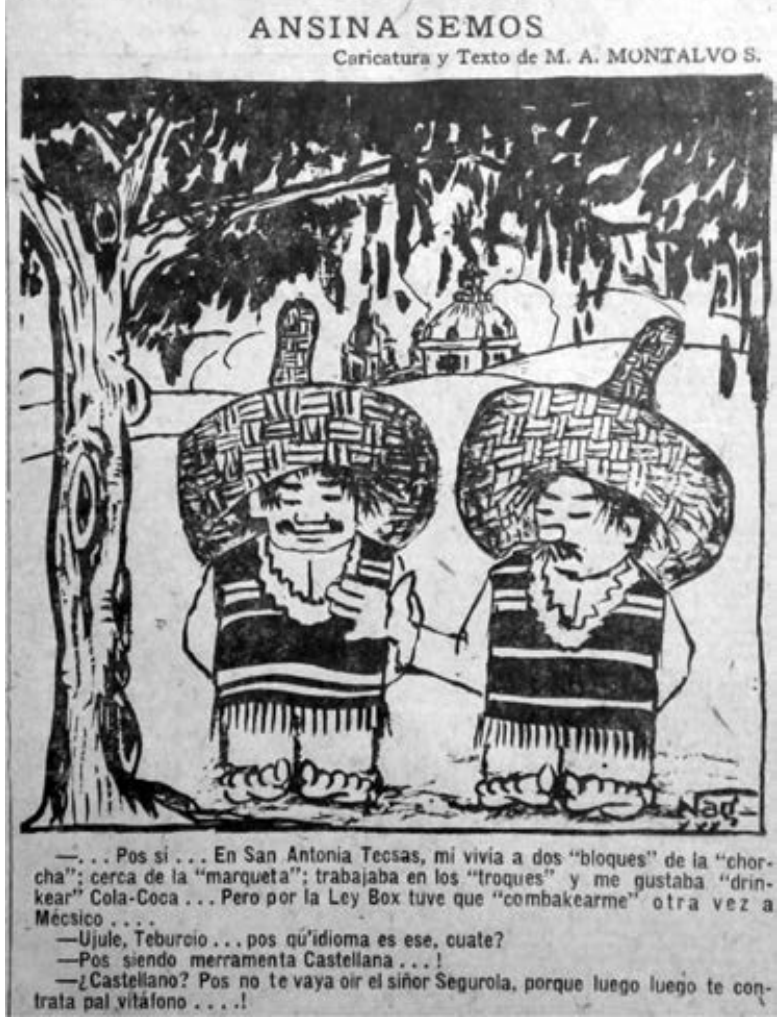

Fuente: El Universal, Ciudad de México (28 mayo 1930).

la naturalización) y la de Extranjería Indeseable (cuyo fin era no permitir el ingreso sin documentación legal y penalizar a aquellos que lo hicieran). Es evidente que los periodistas no diferenciaron la propuesta del congresista texano y las leyes que se promulgaron y los objetivos de estas. La idea de que uno de los objetivos de la "Ley Box" era revisar el estatus de los inmigrantes y la expulsión de estos procedía de la campaña de deportación emprendida en Texas, que se continuó a comienzos de 1930. 
Así, los diarios no lograban entender los objetivos centrales de cada una de las leyes promulgadas a principios de marzo -tampoco la comunidad mexicana en Estados Unidos, razón por la cual hubo una gran confusión, miedo y pánico que hicieron que abandonara ese país-; más bien, los revolvieron y confundieron. Asimismo, malinterpretaron las causas de la migración de retorno, sobre todo en 1929. Lo que hicieron fue atribuirle a la propuesta de Box la mayor parte de las acciones que el gobierno estaba tomando para evitar la entrada de inmigrantes y para promover su expulsión. Ellos, los diarios, inventaron la ley Box.

\section{LAS REACCIONES EN MÉXICO. LEY QUE LASTIMA Y HIERE A LOS MEXICANOS Y A SU PAÍS}

La propuesta de Box fue vista por algunos actores mexicanos como humillante y ofensiva para México y sus ciudadanos, pues se basaba en criterios raciales. Un editorialista de El Siglo de Torreón afirmaba que la iniciativa de restricción estadounidense a la inmigración, basada en diferencias raciales, lastimaba a México y, al mismo tiempo, hería a esa nación. ${ }^{61}$ El Informador conjeturaba que, a partir de la iniciativa de Box, los mexicanos serían divididos en dos categorías para aplicarles "la mencionada leyecita": "los que no son gratos y los que son ingratos". A los primeros se les cerrarían las puertas de entrada a Estados Unidos porque no se les deseaba; a los segundos se les abrirían las puertas para que salieran de ese país, es decir, para que se fueran -este objetivo no estaba planteado en la iniciativa de Box-- ${ }^{62}$ En ambos casos, la idea era que no estuvieran en ese país personas originarias de México. Era una manera de segregar a los ciudadanos procedentes de esa nación. En este sentido, un editorialista de la revista Alas, órgano de la 12a Jefatura de Operaciones Militares,

\footnotetext{
${ }^{61}$ El Siglo de Torreón (22 feb. 1929).

${ }^{62}$ El Informador (20 mayo 1929).
} 
señalaba que el orgullo cegaba a Estados Unidos, pues miraba "pequeños a los hijos del lejano Oriente, a los indolatinos y a los negros". ${ }^{63}$ Un escritor de El Tucsonense opinaba que la propuesta de Box "era humillante" para México. ${ }^{64} \mathrm{El}$ mismo diario, en la nota titulada "El senador Box ataca a los mexicanos", comentaba que Box volvería a acometer contra los mexicanos hasta conseguir que se pusiera una "cuota" a esos migrantes. ${ }^{65}$ La interpretación era que la propuesta de Box constituía una agresión para el pueblo mexicano.

A mediados de 1930, en la Ciudad de México y en otros estados, entre ellos Colima, se difundió el documento titulado "Excitativa de los trabajadores mexicanos", cuyo objetivo era criticar las discusiones que se habían sostenido en el Congreso de Estados Unidos y en el Senado acerca del proyecto de ley presentado por el senador Box. El autor señalaba que las razones que se habían expuesto para esa limitación eran "altamente humillantes para el pueblo mexicano", a quien se consideraba como indigno de pasar al territorio americano por "su inferioridad racial y por sus vicios". Desde su punto de vista, la medida era "altamente ultrajante", más porque se refería exclusivamente a los mexicanos, y no a todos los habitantes del continente americano. ${ }^{66}$ Esta fue una de las mejores interpretaciones que se hicieron de la iniciativa, porque tenía claro cuál era su objetivo y no la mezcló ni confundió con otras legislaciones y otros temas paralelos como la Ley de Extranjería Indeseable, la de Registro de Extranjeros y las deportaciones. El ingeniero Aureliano Leal Treviño, un particular de la Ciudad de México, hizo una amplia propaganda del documento en la capital del país, y coincidía con los puntos de vista expresados en él. Asimismo, consideraba que eran "leyes injustas y vejatorias para la dignidad del

\footnotetext{
${ }^{63}$ Revista Alas (15 mayo 1929).

${ }^{64}$ El Tucsonense (17 abr. 1930).

${ }^{65}$ El Tucsonense (22 dic. 1929).

${ }^{66}$ Periódico Oficial del Estado de Colima (14 jun. 1930).
} 
pueblo mexicano". ${ }^{67}$ Lo que muestran estas declaraciones es la molestia por las propuestas, así como un rotundo rechazo a las iniciativas que proponían una cuota a la migración mexicana a Estados Unidos.

Un editorialista de El Universal, refiriéndose a la iniciativa de Box, expresó que a los mexicanos les ofendían "los planes de limitación a cuotas mínimas para nuestros paisanos". ${ }^{68}$ Por su parte, El Tucsonense consideraba que el orgullo racial de México se vería lastimado, pues con la ley (es decir, la propuesta de Box) se le quería dar a entender que "si no es inferior, sí es, por lo menos, indeseable, que no se le necesita". Asimismo, en alusión a la propuesta de Box, afirmaba que, en lugar de una ley que lastimaba a veintitantos pueblos, se expediría "otra ley que más bien solo perjudica en lo moral que en lo material a una nación, México". El establecimiento de la cuota contra los inmigrantes mexicanos fue definido como un "evento doloroso", con el cual Estados Unidos -nación que estaba "en condiciones de hacer lo que le plazca"- lastimaba a otros pueblos como México. ${ }^{69} \mathrm{La}$ nota mostraba que en el fondo existía enojo y malestar por la iniciativa en importantes sectores de la comunidad mexicana en Estados Unidos.

El Siglo de Torreón afirmaba que México aceptaba que Estados Unidos tenía "perfecto derecho" para darse las leyes necesarias para proteger sus intereses, pero debía hacerlo de tal forma que no resultaran "ultrajantes para un país, denigrantes en altísimo grado", pues establecían diferencias raciales con otros. Pensaba que, mediante el proyecto de Box, Estados Unidos "nos hiere en lo más sensible que tenemos, en nuestro decoro".

\footnotetext{
67 AGENL, sección Correspondencia de Gobernadores. Francisco A. Cárdenas. Año 1930-1932, c. 1. Excitativa a los trabajadores mexicanos firmada por el ingeniero Aureliano Leal Treviño. México, D.F., 2 junio 1930. El Tucsonense (17 abr. 1930).

${ }^{68}$ El Universal (2 feb. 1929).

${ }^{69}$ El Tucsonense (17 abr. 1930).
} 
Aseguraba que la iniciativa "nos denigra, nos ultraja", y por esto no debería aprobarse el proyecto de ley. De igual modo, pensaba que "era un tiro certero que a mansalva daba en el blanco: México", pues se le juzgaba por su inferioridad racial y se le cerraban las puertas so pretexto de proteger a los trabajadores estadounidenses, con lo cual se establecía una comparación con otros países de América Latina. ${ }^{70}$

El editorialista de Torreón interpretaba que la iniciativa de Box juzgaba a México "el peor de los países”, y lo insultaba olvidándose de que tenía en él a uno de los mejores mercados mundiales para su producción. Entonces, hizo un llamado a que los legisladores de Washington tomaran en cuenta que el proyecto había sido formulado por un senador que nunca se había distinguido por su amistad hacia México; por lo tanto, no tenía "ningún derecho para colocarnos en el peor de los casos, vejarnos sin conciencia", porque los estadounidenses que iban a México siempre habían sido bien recibidos, se les había tratado con toda clase de consideraciones y distinciones, habían gozado muchas veces de privilegios que "nuestras leyes niegan a los mexicanos". Por todo ello, hacía un llamado a que se hiciera todo lo posible para que la propuesta de Box no fuera "ignominiosa para México", ya que "nos ultraja y nos denigra, sin que lo merezcamos como hombres y como amigos que somos de los ciudadanos de allende el Bravo". ${ }^{71}$ Más adelante, en el mismo diario se publicó una nota que señalaba que las leyes de inmigración de Estados Unidos "nos insultan con la cuota [la propuesta de Box]" fijada a la entrada de mexicanos en aquel país. Lo peor era que los trabajadores mexicanos seguían emigrando a Estados Unidos sin considerar "esas vergüenzas". ${ }^{72} \mathrm{La}$

70 El Siglo de Torreón (13 jun. 1930).

71 El Siglo de Torreón (13 jun. 1930).

${ }^{72}$ El Siglo de Torreón (8 julio 1930). 
nota daba a entender que la cuota migratoria ya había entrado en vigor y que era una afrenta para el país.

\section{TENSIÓN EN LAS RELACIONES DIPLOMÁTICAS}

Otro tema abordado por la prensa fue el referente al modo en que la propuesta de Box provocó tensión en la relación entre ambos países. Para algunos actores políticos estadounidenses, este fue un aspecto central que llevó a que no se convirtiera en ley. Por el lado mexicano, hasta el momento no hay evidencias de que haya habido una posición, ya que, como se señaló antes, la clase política actuó con prudencia ante un tema que no estaba en la agenda nacional ni internacional, y, sobre todo, porque no se había convertido en ley; hacer declaraciones o pronunciamientos podría contaminar la relación y desgastar el capital político del gobierno por algo que nunca fue. En ese sentido, es posible ver la diferencia de posicionamientos dentro de la sociedad mexicana, pues la clase dirigente evitó hacer declaraciones acerca de la manera en que la propuesta de Box afectaba la relación, mientras que la prensa (conservadora, opositora al gobierno y nacionalista) adoptaba una posición contraria, aun radical, debido al disgusto y el descontento que le causaba la iniciativa.

El Siglo de Torreón publicó una nota en la que afirmaba que la entrada en vigor de la "Ley Box" de forma "retroactiva" desde mayo de 1929 debería ser un punto de discusión entre los gobiernos de ambos países. Se refería al rumor de que la Ley de Extranjería Indeseable se aplicaría de forma retroactiva a partir de mayo. Aseguraba que los subsecretarios de Gobernación y de Relaciones Exteriores de México tendrían una junta para estudiar "este trascendental problema y plantear la representación". La idea era que México exigiera a Estados Unidos -como lo había hecho ese país en las múltiples reclamaciones con motivo de las Leyes del Petróleo para evitar la retroactividad de estas-, 
de acuerdo con el derecho internacional, la no extensión de la aplicación de la "Ley Box" a hechos anteriores a la entrada en vigor de esta. Para ello, se presentarían al Departamento de Estado "datos perfectamente comprobados de la aplicación atentatoria de dicha ley". ${ }^{73}$ La información muestra: a) los rumores y las confusiones entre la iniciativa de Box y la Ley de Extranjería Indeseable, b) el supuesto interés del gobierno mexicano por realizar gestiones diplomáticas a fin de impedir que se aprobaran acciones que afectarían a los inmigrantes mexicanos en ese país, y c) la idea de que la propuesta de Box se estaba aplicando a los inmigrantes mexicanos con el propósito de expulsarlos -aun cuando, en realidad, la iniciativa estaba enfocada en la propuesta de un límite del número de inmigrantes mexicanos; es decir, se confundía, otra vez, el objetivo de la propuesta y las medidas que se estaban aplicando para frenar la migración mexicana y para expulsarla.

En otra nota, El Siglo de Torreón aseguraba que "la nueva Ley Box del vecino país del norte" había hecho que los gobiernos de Estados Unidos y México se enfrentaran para discutir la aplicación del ordenamiento que restringiría la entrada de trabajadores mexicanos al territorio yanqui -hecho del cual no existen pruebas-. ${ }^{74}$ Para algunos observadores, la "Ley Box" había provocado desencuentros entre ambos países. Más tarde, el mismo diario insistiría en que "la restricción de la inmigración mexicana propuesta por Box" podría ser la causa del enfriamiento de las relaciones entre México y Estados Unidos. ${ }^{75}$ De igual manera, consideraba que la propuesta de la Ley Harris lastimaba las relaciones entre los dos países. ${ }^{76}$ Un editorial publicado en El Tucsonense también criticaba con dureza la aprobación de la iniciativa de la Ley Harris-Box. Con ironía, afirmaba que,

${ }^{73}$ El Siglo de Torreón (16 mayo 1929).

74 El Siglo de Torreón (16 mayo 1929).

75 El Siglo de Torreón (15 mayo 1930).

${ }^{76}$ El Siglo de Torreón (24 jun. 1930). 
como una muestra más de buena voluntad y de que las relaciones entre México y Estados Unidos eran “cordiales y amistosas”, el Senado de ese país acababa de aprobar la discutida cuota según la cual solo se autorizaba la entrada de unos 1500 inmigrantes mexicanos cada año. Afirmaba que ello era "una prueba más" de que era "artificial” todo lo que se había dicho en banquetes y fiestas oficiales sobre la "buena voluntad" y las relaciones cordiales y amistosas entre México y Estados Unidos. Además, aseguraba que, ante todo, debía haber amistad y buena voluntad entre ambos pueblos. ${ }^{77}$ Este era el planteamiento acerca de que la discusión de la propuesta de la cuota migratoria a México no favorecería una relación que debería ser cordial.

Otro editorial publicado en El Siglo de Torreón proponía que Estados Unidos debería "ser uno de nuestros amigos más sinceros, tal que nosotros somos suyos”. Además, si México era afectado de alguna manera, sería preciso que se hicieran todas las gestiones necesarias para que la propuesta de Box no se convirtiera en ley. Sugería buscar la manera de acercarse a los legisladores estadounidenses para hacerles ver que no era conveniente que se pusiera en vigor si se quería que no resultasen afectadas las relaciones amistosas y diplomáticas entre ambos países. El escritor, con una visión más clara de lo que sucedía en torno de la iniciativa de Box, demandaba que el gobierno de México hiciera lobby con los actores políticos estadounidenses para que este país no se viera afectado y, sobre todo, la relación no resultase perjudicada. Opinaba que mexicanos y estadounidenses estaban obligados a hacer todo lo posible por estrechar las relaciones porque "somos vecinos geográficamente y tenemos intereses muy unidos”. Creía que, de otra manera, las relaciones entre los dos pueblos se enfriarían, “ahora que se hace lo posible por hacerlas más cordiales a fin de que se resuelvan satisfactoriamente los muchos asuntos que existen pendientes

77 El Tucsonense (17 abr. 1930). 
entre nuestro país y la poderosa nación del Norte". ${ }^{78}$ Las notas publicadas en El Siglo de Torreón y El Tucsonense muestran cómo algunos actores mexicanos pensaron que la iniciativa de Box había creado un ambiente de incertidumbre en las relaciones bilaterales a causa del trato discriminatorio que suponían que México recibiría de parte de Estados Unidos al intentar establecer una cuota a los inmigrantes de ese país.

Otras personas se pronunciaron a favor de que el gobierno mexicano adoptara una actitud más firme ante el gobierno estadounidense respecto de la iniciativa impulsada por el congresista texano. Proponían que, en caso de que la propuesta fuera aprobada, el embajador de México en Estados Unidos, Manuel C. Téllez, presentara una protesta de parte del gobierno mexicano al secretario de Estado, Henry L. Stimson..$^{79}$ En la "Excitativa de los trabajadores mexicanos" también se proponía la realización de "la más enérgica protesta por el ultraje", que consideraba que cometía la "Ley Box", para lo cual demandaba al gobierno mexicano se colocase "a la altura de sus responsabilidades como representante de nuestro pueblo y celoso defensor de su dignidad". 80

El Intruso, diario independiente y satírico fundado en Cananea, Sonora, en 1921 por Santiago Rivas Rodríguez, comentó que, ya que el Senado de Estados Unidos había aprobado una cuota de 1500 mexicanos que podrían entrar de manera legal a Estados Unidos -se refería a la propuesta de ley conocida como Harris-Box-, México debería adoptar medidas similares contra los inmigrantes de otros países, entre ellos Estados Unidos. Además, opinaba que, en estos casos, debería aplicarse la ley del talión, "ojo por ojo y diente por diente". Si los códigos estadounidenses prohibían la entrada de braceros mexicanos, con

78 El Siglo de Torreón (13 jun. 1930).

79 El Siglo de Torreón (12 mayo 1929). El Universal (16 y 22 mayo 1929).

80 Periódico Oficial del Estado de Colima (14 jun. 1930). 
mayor razón habría de restringirse la inmigración de extranjeros al centro de México. ${ }^{81}$ En el panfleto titulado "Excitativa de los trabajadores mexicanos" se proponía que se efectuara un boicot contra los productos estadounidenses. Sugirió que este debería ser encabezado por los trabajadores y tendría el objetivo de "hacer comprender al pueblo americano que resentimos el ultraje”. Asimismo, afirmaba que si el gobierno estadounidense atacaba los intereses de los mexicanos y, al mismo tiempo, tenía la puerta abierta en todas partes para ejercer sus actividades, México también estaba en capacidad de cerrar la puerta al comercio de ese país. ${ }^{82}$ En el mismo sentido, Rodolfo Uranda, editorialista de El Tucsonense, demandaba que el gobierno de México confrontara abiertamente a Estados Unidos mediante el boicot comercial encabezado por los trabajadores en México. ${ }^{83}$ Consideraba que esto sería más eficaz que todas las gestiones diplomáticas que la Cancillería pudiera hacer. Afirmaba que la industria estadounidense necesitaba los mercados de América Latina, entre los cuales México ocupaba un lugar preferente; si poco a poco se le cerraban esos mercados, los legisladores de Washington, influidos por intereses económicos, recapacitarían antes de expedir "una ley a todas luces injusta y vejatoria de nuestra dignidad racial”. ${ }^{84}$ Tal como lo señaló el editorialista de la revista Alas, la propuesta causó resentimientos en México, razón por la cual surgieron propuestas de represalias contra ese país y sus ciudadanos, pues hubo quienes se pronunciaron por un boicot comercial a Estados Unidos y por aplicar con rigor las leyes migratorias y laborales a los ciudadanos estadounidenses que estaban en México. El mismo escritor consideraba que era una contradicción que el país que se pronunciaba por "la paz y el

\footnotetext{
${ }^{81}$ El Intruso, Diario Joco-Serio (16 mayo 1930).

82 Periódico Oficial del Estado de Colima (14 jun. 1930).

${ }^{83}$ El Tucsonense (17 abr. 1930).

${ }^{84}$ Periódico Oficial del Estado de Colima (14 jun. 1930). Alanís, “Ojo por ojo, diente por diente”, pp. 378-402.
} 
amor en todo el orbe" promoviera una ley que pretendía limitar la inmigración mexicana, al mismo tiempo que echaba de ese país a miles de personas, lo cual en realidad estaba sucediendo. Esto, según él, lo que hacía era minar el prestigio estadounidense, su calidad moral como nación. La nota mostraba la molestia por el intento de limitar la migración procedente de México, la idea de que esta iniciativa era también para expulsar a miles de mexicanos en Estados Unidos -lo cual nunca se había planteado- y el desprestigio de Estados Unidos a causa de esta medida. Era una vergüenza debido a que era una gran nación y a los valores que defendía: democracia y libertad. ${ }^{85}$

Un sector de la sociedad mexicana estaba a favor de que su gobierno tomara una posición más firme en materia de diplomacia, así como en política migratoria y comercial, contra Estados Unidos, como respuesta a la iniciativa de Box. Esto se debía, en parte, a la ola nacionalista y de xenofobia contra ese país, que se había originado a comienzos del siglo a raíz de las intervenciones que llevó a cabo en México y que había tomado fuerza en los años veinte. A pesar de ello, no hay constancia de que el gobierno mexicano haya planteado en algún momento una demanda formal. Tampoco se sabe que haya sido motivo de discusión entre actores oficiales mexicanos y estadounidenses. En realidad, ninguno de los dos gobiernos estaba dispuesto a desgastar la relación por una propuesta de ley que nunca fue aprobada. Los pronunciamientos más agresivos y radicales procedían de sectores no oficiales.

La posición del gobierno de México ante la iniciativa de Box estuvo determinada en gran parte por la manera en que otros habían actuado ante la migración de nacionales al Norte desde comienzos del siglo xx. En primer lugar, fue manifiesta la preocupación de algunos integrantes de la clase política por la manera en que esa iniciativa afectaría a sus nacionales, y cómo

85 Revista Alas (15 mayo 1929). 
se les defendería. Carlos Riva Palacio, secretario de Gobernación, mostró zozobra por la forma en que la "Ley Box" podría "afectar a los mexicanos" residentes en Estados Unidos. ${ }^{86}$ Por su parte, el embajador de México en Washington se mostró a favor de los mexicanos respecto de la cuota. ${ }^{87}$ En tanto, el Departamento de Migración de la Secretaría de Gobernación inició un estudio "meditado de la Ley Box" a fin de valorar cómo esta afectaría los intereses de los trabajadores mexicanos. ${ }^{88} \mathrm{De}$ las declaraciones de los funcionarios y del estudio promovido por Gobernación se desprenden dos aspectos. El primero es la defensa de los mexicanos en el exterior, la cual formaba parte de una de las iniciativas más importantes del gobierno desde comienzos del siglo. ${ }^{89} \mathrm{El}$ segundo es el estudio hecho con el objeto de valorar los efectos que tendría la propuesta en la migración laboral mexicana; es decir, deja ver cierta preocupación en las altas esferas oficiales por el posible impacto de los flujos migratorios entre México y Estados Unidos, tanto el de salida como, sobre todo, el de retorno. En cuanto al primero, como se verá más adelante, la inquietud no debió ser grande, pues, en la visión oficial, ayudaría a cumplir una de las metas que se habían propuesto los gobiernos desde principios del siglo: frenar la migración. El retorno de cientos de nacionales era el asunto que más inquietaba porque, a pesar de que algunos soñaban con formar colonias agrícolas con ellos, así como aprovechar sus "grandes capacidades" adquiridas durante su permanencia en Estados Unidos, no había una idea de cómo hacerle frente, ni medidas para ello, salvo la ayuda en el pasaje de ferrocarril para trasladar a los más necesitados a sus lugares de origen, como había sido una tradición desde comienzos del siglo, sobre todo en

\footnotetext{
${ }^{86}$ El Siglo de Torreón (12 mayo 1929). El Universal (16 y 22 mayo 1929).

87 El Universal (22 mayo 1920). El Intruso (27 mayo 1930).

${ }^{88}$ El Siglo de Torreón (16 mayo 1929; 16 y 27 mayo, 2 y 24 jun. 1930).

89 Alanís, "Que vayan y se queden allá”, pp. 351-384.
} 
los momentos en que se efectuaron deportaciones de nacionales en gran escala (1907 y 1921).

\section{LO POSITIVO DE LA PROPUESTA BOX PARA MÉXICO}

La iniciativa de John Box no solo fue vista por algunos integrantes de la sociedad mexicana como un insulto para este país y sus ciudadanos y motivo de fricción entre ambas naciones; también algunos observadores consideraron que reportaría beneficios para México. Se pensó, sobre todo, que ayudaría a concretar el sueño oficial de frenar la emigración a Estados Unidos y, mediante la migración de retorno que se produciría (la llamada repatriación, como se le conocía entonces), se contribuiría a colonizar algunas regiones del país con personas que supuestamente tenían capacidades especiales adquiridas durante su estancia en Estados Unidos.

A comienzos de 1929, según estudios realizados por la Secretaría de Gobernación, la "Ley Box" sería beneficiosa para México, ya que mediante esta terminaría la emigración de mexicanos al vecino país. ${ }^{00}$ Esta era una parte central de la visión oficial sobre la salida de sus nacionales a Estados Unidos. El Siglo de Torreón suponía que esa ley facilitaría "la campaña del gobierno mexicano para impedir la salida de los braceros”. Además, ello contribuiría a que el gobierno procurara el mejoramiento de las condiciones de trabajo existentes en la República. ${ }^{91}$ En el mismo sentido, un editorialista de El Tucsonense consideraba que México nada perdería con la aprobación de la "Ley Box", sino "al contrario", pues el gobierno estaba haciendo esfuerzos para evitar la emigración de nacionales a aquel país, por medio de la información y la comunicación de las circunstancias en que vivían los mexicanos en Estados Unidos, haciéndoles ver

90 El Siglo de Torreón (22 feb. 1929).

${ }^{91}$ El Siglo de Torreón (10 ago. 1929). 
el sinnúmero de trabajos por los que tenían que pasar. Entonces, el deseo de Estados Unidos de terminar con la caravana de inmigrantes mexicanos no era "mayor que el del gobierno de México". Por ello, México salía ganando con la propuesta de Box. Así, con la aprobación de la ley, Estados Unidos obtendría su objetivo: recibir a un limitado número de inmigrantes mexicanos. Por su parte, con la misma ley, México vería realizada su aspiración de que "sus hijos no abandonen la patria". ${ }^{92}$

El Siglo de Torreón opinaba que la iniciativa de Box "materialmente no nos perjudica", sino, al contrario, beneficiaría a los mexicanos porque impediría, "como nuestro gobierno viene deseando hacerlo hace muchos años", la emigración de "nuestros trabajadores", sobre todo de "los más aptos, los mejores, los que aquí necesitamos para resolver nuestros problemas interiores" en materia de producción y economía. Ello también impediría que allá sufrieran discriminación y malos tratos: ya no sufrirían vejaciones, ni sus hijos serían enviados a las escuelas de negros, ni se los echaría de los salones de baile "por el enorme delito de ser mexicanos y hablar en español". También impediría que se encontraran "de la noche a la mañana sin trabajo", tras haber sufrido "mil malos tratos" de los capataces, ser encarcelados por vagos y deportados "muertos de hambre o locos, inservibles", para que fueran a México a aumentar el número de individuos desempleados. Así, la "Ley Box" sería más efectiva que toda la propaganda que en México se había llevado a cabo para impedir que los braceros fueran "en busca de El Dorado a las tierras del Tío Sam". 93

Igualmente, algunos consideraban que "las miles" de deportaciones que se efectuarían por la "Ley Box" (interpretación exagerada que he señalado a lo largo del trabajo y que corresponde a la campaña federal de expulsión en el sur de Texas)

92 El Tucsonense (17 abr. 1930).

${ }_{93}$ El Siglo de Torreón (13 jun. 1930). 
serían positivas para México, pues esa situación podría ser aprovechada por la Comisión Nacional de Irrigación (CNI), organismo dependiente de la Secretaría de Agricultura y Fomento, creada en 1926 para promover, construir y operar obras de irrigación, a fin de impulsar la colonización de las grandes extensiones de terreno que estaban a lo largo de la frontera norte. Ello contribuiría también a evitar "infiltraciones extrañas" que provocarían la desintegración de "nuestro territorio” (aún persistía el miedo a una posible invasión de Estados Unidos y a la pérdida de territorio con ese país, como había sucedido a mediados del siglo XIX). ${ }^{94} \mathrm{La}$ "Ley Box" fue bien vista por ciertos sectores gubernamentales mexicanos porque México se vería beneficiado con el retorno de "agricultores expertos". En Sinaloa, El Demócrata Sinaloense, periódico estatal cercano a las posiciones gubernamentales, afirmaba que "todos los agricultores mexicanos residentes en Texas, perfectos conocedores de los cultivos, afectados por las recientes leyes migratorias de los Estados Unidos [entre ellas, la ley Box] estaban pensando muy seriamente regresar a la República a fin de colonizar vastas regiones, si el gobierno les da facilidad para ello" ${ }^{95}$ La nota muestra el clima de intranquilidad en el que vivían muchos mexicanos a consecuencia de las leyes promulgadas a comienzos de 1929, el miedo a ser expulsados debido a la campaña federal de deportación emprendida en ese estado de la Unión Americana y, otra vez, la atención a la iniciativa de Box, que se mezcló con esas legislaciones y las expulsiones. También manifestaba uno de los sueños oficiales más socorridos de entonces: que migrantes con experiencia laboral en Estados Unidos regresaran a México a poblar y producir en algunas regiones a fin de impulsar el desarrollo de estas, en especial en zonas de riego. Para algunos, la iniciativa de Box contribuiría a lograr ese objetivo, así como a

94 El Siglo de Torreón (12 jul. 1929).

95 Carton de Grammont, “La presencia norteamericana”, pp. 6-7. 
frenar la migración, lo cual también añoraban muchos sectores de la sociedad mexicana.

Las opiniones de El Siglo de Torreón y El Tucsonense en torno de los potenciales efectos favorables de la propuesta del congresista Box en México reflejaban lo que pensaba una amplia capa de la opinión pública mexicana en esa época. La idea de que la migración de trabajadores a Estados Unidos debía ser frenada venía desde principios del siglo xx.. ${ }^{96}$ Desde entonces, por medio de la prensa, los gobiernos habían llevado a cabo en diversas regiones una intensa campaña contra la salida, que se incrementó en 1929, cuando las presidencias municipales alertaron de los requisitos para obtener una visa en los consulados estadounidenses. ${ }^{97}$ Asimismo, en el ánimo de un amplio sector de la sociedad de esa década prevalecía la idea nacionalista de que los mexicanos no debían emigrar a otro país, que primero habrían de trabajar en México para evitar que fueran explotados y maltratados en Estados Unidos. Estos puntos de vista fueron reproducidos en numerosos editoriales de la prensa de diversas tendencias ideológicas a lo largo del territorio nacional. ${ }^{98}$ Por su parte, en amplios sectores de la sociedad también fue compartida la idealización de los migrantes como seres superdotados, con cualidades laborales e intelectuales, que podrían venir a colonizar regiones. Diversos editoriales alababan las cualidades de los migrantes y el supuesto impacto que su retorno tendría con la fundación de colonias agrícolas o su establecimiento en zonas de riego. Manuel Gamio, el famoso antropólogo mexicano que a finales de la década hizo investigación sobre la migración mexicana, fue uno de los intelectuales más representativos de estas ideas, así como el ingeniero Javier Sánchez Mejorada, uno de los más importantes representantes de la CNI, quien durante

\footnotetext{
${ }^{96}$ González Navarro, "Los braceros en el porfiriato", pp. 9-26.

97 AGMA, Circular del Departamento de Migración, exp. 658/13, mayo 1929.

98 Cardoso, Mexican Emigration, pp. 96-118.
} 
la segunda mitad de la década de los veinte se pronunció por la colonización en zonas de riego con migrantes que hubieran laborado en los campos agrícolas del suroeste de Estados Unidos. Una amplia capa de la opinión pública veía con buenos ojos que cierto tipo de migrantes regresaran a México a fundar nuevos establecimientos; pensaba que con ello el país aprovecharía las capacidades de estos, al tiempo que contribuirían al desarrollo de ciertas regiones y, en general, del país. ${ }^{99}$

\section{CONCLUSIONES}

El análisis de la propuesta de John Box y de la atención que le dio la prensa mexicana lleva a dos conclusiones. La primera es que el interés mostrado por los editorialistas y escritores de algunos periódicos en 1929 y comienzos de 1930 no fue en sí por la propuesta de Box, sino por aquellas medidas que el gobierno de Estados Unidos tomó para controlar la migración legal e ilegal de mexicanos, así como para expulsarlos de su territorio. Es decir, lo que en realidad llamó la atención, preocupó y enfadó a algunos periodistas, $\mathrm{y}$ a otros actores de la sociedad mexicana, fue el hecho de que el gobierno de Estados Unidos estuviera efectuando deportaciones, aplicando medidas para impedir el ingreso de mexicanos -por medio de la limitación del número de visas, aspecto que fue relevante en la política del Departamento de Estado, pero que pocas veces los editorialistas comprendieron y sobre el cual hubo escasos pronunciamientos, como lo muestra este trabajo-, así como las penalizaciones establecidas para quienes ingresaron sin documentos legales (la Ley del 4 de marzo). La explicación de todo ello, según ellos, fue la "Ley Box". Así, la mayoría de los contemporáneos no logró entender con claridad lo que estaba sucediendo: la implementación de diversas medidas para controlar el ingreso de mexicanos y para

99 Alanís, “Mexicanos procedentes de Estados Unidos”, pp. 1673-1680. 
expulsarlos, y las legislaciones, cuyo objetivo central no eran los migrantes de México, sino la inmigración en general, que reforzaban estas acciones: la Ley de Registro de Extranjeros y la de Extranjería Indeseable ( 2 y 4 de marzo, respectivamente) -que despertaron una gran confusión entre la prensa y la comunidad mexicana en Estados Unidos-. Interpretaban lo que sucedía mediante la iniciativa de Box, la cual tuvo una amplia publicidad, pero nunca se concretó.

La segunda conclusión es que 1929 es una etapa excepcional de la historia de la migración mexicana. Es un periodo que merece un estudio exhaustivo y una reinterpretación, pues los estudios clásicos, así como las periodizaciones tradicionales, lo ubican como parte de la historia de las deportaciones de la Gran Depresión. No obstante, como lo muestra este trabajo, las expulsiones de 1929 y principios de 1930 respondieron a circunstancias que no estaban relacionadas con la recesión, sino con una respuesta oficial hacia los grupos nativistas que habían tenido poco éxito en el establecimiento de una ley que impusiera una cuota migratoria a México. En ese sentido, las medidas tomadas en ese año por el gobierno de Estados Unidos fueron la culminación de un proceso que posiblemente inició en 1920 -con algunos antecedentes en la década anterior-, cuando surgieron voces racistas, nativistas y xenófobas en el Congreso y en otros niveles de esa sociedad contra la inmigración mexicana $\mathrm{y}$ a favor del establecimiento de una ley que incluyera a México en las cuotas migratorias. A finales de la década, esas voces no lograron la aprobación de una ley, pero sí algo de igual importancia: la adopción de medidas para que los migrantes mexicanos no ingresaran y para expulsarlos, antes de la recesión. En ese contexto, esta etapa también significó para México la conclusión de un ciclo que probablemente había comenzado desde finales del siglo XIX, en el cual se hizo más evidente la posición que parte de la sociedad y la clase política adoptarían respecto de las medidas tomadas por Estados Unidos para controlar los 
flujos migratorios entre ambas naciones: la publicidad contra la emigración, el deseo de que esta desapareciera porque se consideraba una vergüenza para el país y sus gobernantes, la idealización en torno de las aptitudes de los migrantes de retorno -"sus grandes cualidades laborales e ideológicas” que, supuestamente, podrían ser aprovechadas en México con la fundación de colonias agrícolas y en los sistemas de riego-, el enojo causado por las deportaciones de nacionales ejecutadas por las autoridades estadounidenses, la idea de que ello friccionaba las relaciones bilaterales y, en general, el malestar originado por las iniciativas contra la inmigración mexicana.

\section{SIGLAS Y REFERENCIAS}

AGENL Archivo General del Estado de Nuevo León, México.

AGMA Archivo General Municipal de Aguascalientes, México.

Alanís Enciso, Fernando Saúl, Voces de la repatriación. La sociedad mexicana y la repatriación de mexicanos de Estados Unidos, 1930-1933, México, El Colegio de San Luis, El Colegio de la Frontera Norte, El Colegio de Michoacán, 2015.

Alanís Enciso, Fernando Saúl, "Mexicanos procedentes de Estados Unidos en los sistemas de riego", en Historia Mexicana, LxIv: 4 (256) (abr.-jun. 2015), pp. 1667-1728.

Alanís Enciso, Fernando Saúl, “Ojo por ojo, diente por diente. Propuesta en México ante la deportación de mexicanos en Estados Unidos, 19301933", en Mexican Studies/Estudios Mexicanos, 34: 3 (2018), pp. 378-402.

Alanís Enciso, Fernando Saúl, “Que vayan y se queden allá. La política mexicana hacia la migración a Estados Unidos", en Schiavon, Spencer y VÁzquez Olivera (eds.), 2006, pp. 351-384.

Allerfeldt, Kristofer, “And We Got Here First: Albert Johnson, National Origins and Self-Interest in the Immigration Debate of the 1920s", en Journal of Contemporary History, 45: 1 (ene. 2010), pp. 7-26.

Balderrama y Rodríguez, Decade of Betrayal. Mexicans Repatriated in the 1930s, Albuquerque, Nuevo Mexico, University of New Mexico Press, 1995. 
Bulletin of the United States Bureau of Labor Statistics, Immigration Legislation, Years Ending June 30, 1929 and 1930, U.S. Government Printing Office, 1931.

CARdoso, Lawrence, Mexican Emigration to the United States 1897-1931, Arizona, The University of Arizona Press, 1980.

Carreras de Velasco, Mercedes, Los mexicanos que devolvió la crisis 19291932, México, Secretaría de Relaciones Exteriores, 1974.

Carton de Grammont, Hubert, "La presencia norteamericana en el agro sinaloense en la primera mitad del siglo xx", en Secuencia, 7 (ene.-abr. 1987), pp. 5-23.

Conwin, Arthur, F., "A Story of Ad Hoc Exemptions: American Policy Toward Mexico”, en Corwin (ed.), 1978, pp. 136-175.

Conwin, Arthur F. (ed.), Immigrants and Immigrants Perspectives on a Mexican Labor Migration to the United States, Westport, Greenwood Press, 1978.

Corwin, Arthur F. y Johnny M. McCain, "Wetbackism since 1964: A catalogue of factors”, en CoRwin (ed.), 1978, pp. 67-107.

Covarrubias Velasco, Ana, "Los principios y la política exterior de México”, en Schiavon, Spencer y Vázquez Olivera (eds.), 2006, pp. 387-422.

Divine, Robert, American Immigration Policy, 1924-1952, New Haven, Connecticut, Yale University Press, 1957.

ETTINGER, Patrick, Imaginary Lines; Border Enforcement and the Origins of Undocumented Immigration, 1882-1930, Austin, Texas, University of Texas Press, 2009.

Foley, Neil, The White Scourge: Mexicans, Blacks, and Poor Whites in Texas Cotton Culture, Berkeley, University of California Press, 1997.

Gamio, Manuel, Número, procedencia y distribución geográfica de los inmigrantes mexicanos en los Estados Unidos, México, Talleres Gráficos Diario Oficial, 1930.

Garza, Melita M., They Came to Toil: Newspaper Representations of Mexicans and Immigrants in the Great Depression, Austin, Texas, University of Texas Press, 2018. 
González Navarro, Moisés, "Los braceros en el Porfiriato", en Estudios Agrarios, 44 (mayo-ago. 2010), pp. 9-26.

Hernández, Lytle Kelly, Migra!: A History of the U.S. Border Patrol, Berkeley, University of California Press, 2010.

Hoffman, Abraham, "El cierre de la puerta trasera norteamericana-restricción de la inmigración mexicana", en Historia Mexicana, xxv: 3 (99) (ene.-mar. 1976), pp. 403-422.

KAng, S. Deborah, The ins on the Line: Making Immigration Law on the usMexico Border, 1917-1954, Oxford, Oxford University Press, 2017.

Knight, Alan, U.S.-Mexican Relations, 1910-1940: An Interpretation, San Diego, University of California, Center for U.S.-Mexican Studies, 1987.

Lukens, D. Patrick, A Quiet Victory for Latino Rights: fdr and the Controversy Over "Whiteness", Arizona, The University Arizona Press, 2012.

Marshall Roderick, B. A., "The 'Box Bill': Public Policy, Ethnicity, and Economic Explotation in Texas”, tesis de maestría, Universidad de San Marcos, Texas, 2011.

Mckay, R. Raynolds, "Texas Mexican Repatriation during the Great Depression”, tesis de doctorado en filosofía, The University of Oklahoma at Norman Graduate College, 1982.

MeYer, Lorenzo, México y los Estados Unidos en el conflicto petrolero (19171942), México, El Colegio de México, 1981.

Meyer, Lorenzo, Rafael Segovia y Alejandra Lajous, Historia de la Revolución Mexicana, vol. 12. Estado y sociedad con Calles, México, El Colegio de México, 1995.

Molina, Natalia, "In a Race All Their Own: The Quest to Make Mexicans Ineligible for U.S. Citizenship”, en Pacific Historical Review, 79: 2 (2010), pp. 167-201.

Montejano, David, Anglos and Mexicans in the Making of Texas, 1836-1969, Austin, Texas, University of Texas Press, 1987.

MurRIETA, Manuel, "El general Obregón, poeta revolucionario en Arizona”, en Dossier Político, Periodismo Inteligente, consultado en http://www.dossier- 
politico.com/vernoticiasanteriores .php?artid=97618\&relacion=dossierpolitic o\&criterio $=$ General ( 2 de enero 2019).

NgaI, Mae, "The Strange Career of the Illegal Alien: Immigration Restriction and Deportation Policy in the United States, 1921-1965", en Law and History Review, 21: 1 (primavera 2003), pp. 69-107.

NgaI, Mae, Impossible Subjects: Illegal Aliens and the Making of Modern America, Princeton, New Jersey, Princeton University Press, 2004.

Otey, George N., "Shrugging Atlas: The Box Bills and U.S. Attitudes Regarding Mexican Migration in the 1920s", consultado en https:// shareok.org/bitstream/handle/11244/18502/Thesis1987R-O97s. pdf?sequence $=1$ \&isAllowed $=y-$.

ReIsler, Mark, "Always the Laborer, Never the Citizen: Anglo Perceptions of the Mexican Immigrant During the 1920s", en Pacific Historical Review, 45: 2 (1976), pp. 231-254.

ReISLER, Mark, By the Sweat of their Brown: Mexican Immigrant. Labor in the United States, 1900-1940, Westport, Connecticut, Greenwood Press, 1976.

Riguzzi, Paolo y Patricia de los Ríos, Las relaciones México-Estados Unidos, 1756-2010, II: ¿ Destino no manifiesto? 1867-2010, México, Universidad Nacional Autónoma de México, Secretaría de Relaciones Exteriores, 2012.

SÁnchez Ruiz, Enrique, "Apuntes para una historia de la prensa en Guadalajara”, consultado en http://www.publicaciones.cucsh.udg.mx/pperiod/ comsoc/pdf/4-5_1989/10-38.pdf.

Schiavon, Jorge A., Daniela Spencer y Mario Vázquez Olivera (eds.), En busca de una nación soberana. Relaciones internacionales de México, siglos xix $y x x$, México, Centro de Investigación y Docencia Económicas, Secretaría de Relaciones Exteriores, 2006.

Vázquez, Josefina Zoraida y Lorenzo Meyer, México frente a Estados Unidos. Un ensayo histórico, 1776-1980, México, Fondo de Cultura Económica, 1982.

WaLSH, Casey, Building the Borderlands: A Transnational History of Irrigated Cotton along the Mexico Texas Bordor, College Station, Texas, A\&M University Press, 2008. 
Weber, John, "Homing Pigeons, Cheap Labor, and Frustrated Nativists: Immigration Reform and the Deportation of Mexicans from South Texas in the 1920s", en The Western Historical Quarterly, 44: 2 (primavera 2013), pp. 167-186.

Yankelevich, Pablo, "América Latina en la agenda diplomática de la revolución mexicana”, en Schiavon, Spencer y Vázquez Olivera (eds.), 2006, pp. 277-312.

Young, Julia, "Cristero Diaspora: Mexican Emigrants, the U.S. Catholic Church, and Mexico's Cristero War, 1926-1929”, en The Catholic Historical Review, 98: 2 (abr. 2012), pp. 271-300.

Young, Julia, Mexican Exodus: Religion, Migration, and the Long Legacy of Mexico's Cristero War, Oxford, Oxford University Press, 2015.

Zolberg, Aristide R., A Nation by Design: Immigration Policy in the Fashioning of America, Nueva York, Harvard University Press, 2006. 
